\title{
Differential Scanning Calorimetry of Lipids of Stored Apples ${ }^{\dagger}$
}

\author{
Shigeaki Kimura, Satoru Yamashita \\ and Tatsuo OKАмото \\ Laboratory of Use of Horticultural Products, Faculty of Agriculture, \\ Hirosaki University, 3, Bunkyo-cho, Hirosaki-shi, \\ Aomori 036, Japan
}

Received September 30, 1985

\begin{abstract}
The total lipids of Ralls Janet apples' mitochondria after six-month storage at $0^{\circ} \mathrm{C}$ were examined by differential scanning calorimetry (DSC). The phase change temperature was $-85^{\circ} \mathrm{C}$, differing from that of Starking Delicious apples. The total lipids were extracted from the pulp of Ralls Janet apples after eleven months of storage and fractionated into neutral lipid, glycolipid, and phospholipid fractions by column chromatography on silicic acid. These fractions were measured by DSC. The glycolipid fraction contributed to the phase change temperature at $-85^{\circ} \mathrm{C}$. Furthermore, the spot having an $R f$ value of 0.43 on thin-layer chromatography contributed to the phase change temperature. The glycolipid fraction may contribute to cold tolerance.
\end{abstract}

Lyons ${ }^{1)}$ reported a correlation between the contents of unsaturated fatty acids and the chilling injury tolerance of plants and fruits. He also discussed whether functions of fluidity, flexibility and transport in the mitochondrial membranes were kept in an active state during cold storage.

Murata $^{2)}$ reported the existence of coldsensitive substances, the two kinds of substances of molecular species of phosphatidylglycerol. Raison et al. ${ }^{3)}$ reported that a shift of the phase change temperature was the first step of chilling injury in biological membranes.

Kimura et $a l .{ }^{4)}$ reported the contents of unsaturated fatty acids, and the PC/PE content ratio in the pulp and mitochondria of Starking Delicious and Ralls Janet apples.

Chilling injury seldom occurs during cold storage and controlled atmosphere storage in Ralls Janet apples. In our previous paper, ${ }^{5)}$ we reported that the phase change temperature was observed near $20^{\circ} \mathrm{C}$ in the pulp of Ralls Janet and Starking Delicious apples just after harvest, but shifted to lower temperatures after six months of cold storage. The phase change temperature of the glycolipid fraction in the pulp of Ralls Janet was lower than in that of Starking Delicious. This glycolipid fraction in the pulp of Ralls Janet may contribute to the cold tolerance. Furthermore, we thought that the cold tolerance substance may be synthesized during cold storage, considering that the phase change temperature was lowered.

\section{MATERIALS}

Ralls Janet apples and Starking Delicious apples were harvested at Fujisaki Farm, Hirosaki University, in 1982 and stored at $0^{\circ} \mathrm{C}$.

\section{METHODS}

The preparation of mitochondria. Apples were grated in a cold grinding medium of $0.5 \mathrm{~m}$ saccharose, $0.1 \%(\mathrm{w} / \mathrm{v})$ bovine serum albumin (BSA), $0.01 \mathrm{M}$ EDTA, $0.5 \% \mathrm{~L}-$ cysteine, $0.01 \mathrm{M}$ phosphate buffer, sea sand, and $20 \% \mathrm{w} / \mathrm{v})$ polyclar-AT. The $\mathrm{pH}$ was kept at 7.0 by addition of $0.1 \mathrm{M}$ potassium hydroxide. The mixture was ground for $30 \mathrm{~min}$ in a mortar and then squeezed. The filtrate was centrifuged at $1,000 \mathrm{~g}$ for $10 \mathrm{~min}$ to remove cell debris. Then the

$\uparrow$ Studies on Chilling Injury of Apples. Part VIII. See refs. 4 5. 
supernatant was passed through a Sephadex G-25 (coarse) column to remove polyphenol substances. The eluate was centrifuged at $10,000 \mathrm{~g}$ for $30 \mathrm{~min}$ and then the precipitate was washed with a washing medium of $0.5 \mathrm{~m}$ saccharose, $0.1 \%(\mathrm{w} / \mathrm{v}) \mathrm{BSA}$, and $0.01 \%$ phosphate buffer ( $\mathrm{pH} 7.0$ ). Afterwards, the suspension of washed precipitate in the washing medium was centrifuged at $10,000 \mathrm{~g}$ for $30 \mathrm{~min}$. The mitochondria were suspended in the washing medium and kept in ice water. This was done at $0^{\circ} \mathrm{C}^{4)}$

The extraction of total lipid from the apples. After removal of peel and core, the pulp was cut in small pieces and homogenized for $10 \mathrm{~min}$ with ten volumes of chloroform-methanol $(2: 1, \mathrm{v} / \mathrm{v})$ by Folch's method, 0.2 volume of water was added to the total extracts, and the mixture was left overnight. The lower layer was collected and evaporated in a vacuum at $40^{\circ} \mathrm{C}^{4}$ )

The fractionation of total lipid into neutral lipid, glycolipid, and phospholipid fractions by column chromatography. Neutral lipids, glycolipids, and phospholipids were separated from total lipids by column chromatography on silicic acid by Vorbeck's method; the neutral lipids were fractionated with chloroform, glycolipids with chloroform-acetone $(1: 1, \mathrm{v} / \mathrm{v})$, acetone and acetone-methanol $(98: 2, v / v)$, and phospholipids with a mixture of chloroform and methanol in the ratio $(\mathrm{v} / \mathrm{v})$ of $8: 2$ and then methanol. ${ }^{6)}$

Differential scanning calorimetry. For differential scanning calorimetry (DSC) we used a Rigaku-Denki Calorimeter (Model MJ 810), scanning at the rate of $5^{\circ} \mathrm{C} \mathrm{K} / \mathrm{sec}$ with the instrument operating at the sensitivity of $0.5 \mathrm{~m} \mathrm{cal} / \mathrm{sec}$ and the temperature region from $-150^{\circ} \mathrm{C}$ to $100^{\circ} \mathrm{C}$ using liquid nitrogen. ${ }^{5)}$
Thin-layer chromatography of glycolipids fraction. The solvent for thin-layer chromatography was di-isobutylketone-acetic acid-water $(40: 20: 4, \mathrm{v} / \mathrm{v})$ on Merck's thinlayer plates (Art 5721). After development, the spots were detected by anthrone reagent. ${ }^{7)}$

\section{RESULTS AND DISCUSSION}

The phase change temperature of total lipids in the mitochondria of Ralls Janet and Starking Delicious after six months of storage at $0^{\circ} \mathrm{C}$ A broad endothermic peak was observed at $-80 \sim 50^{\circ} \mathrm{C}$, having a maximum endothermic temperature at $-50^{\circ} \mathrm{C}$, and near $0^{\circ} \mathrm{C}$ in the mitochondria of Starking Delicious after storage for six months at $0^{\circ} \mathrm{C}$ (Fig. 1). On the other hand, a sharp endothermic peak was observed at $-85^{\circ} \mathrm{C}$ and broad endothermic peak was observed near $0^{\circ} \mathrm{C}$ in the mitochondria of Ralls Janet (Fig. 1).

The phase change temperature of lipids fractionated by column-chromatography in the pulp of Ralls Janet after eleven months of storage at $0^{\circ} \mathrm{C}$ and qualitative analysis of the lipids by thin-layer chromatography

The endothermic peak of phase change temperature was $-85^{\circ} \mathrm{C}$ in total lipids of the Ralls Janet apples' mitochondria. To investigate what kinds of lipids corresponded to this peak, total lipids extracted from the pulp of Ralls

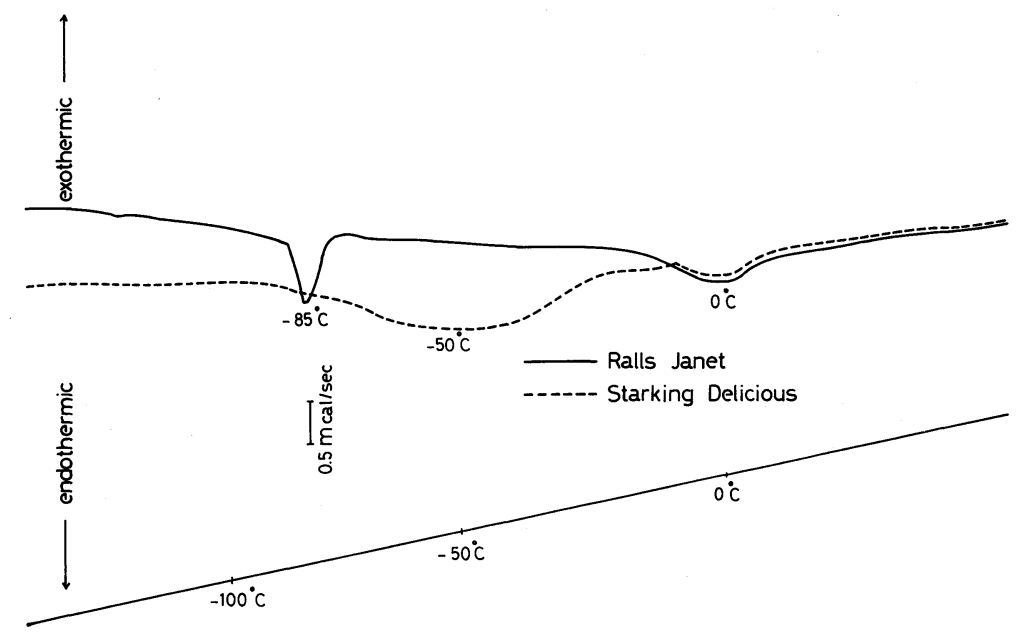

FIG. 1. Thermogram of Differential Scanning Calorimetry of Total Lipids in Starking Delicious and Ralls Janet Apples' Mitochondria after Six Months of Storage at $0^{\circ} \mathrm{C}$. 


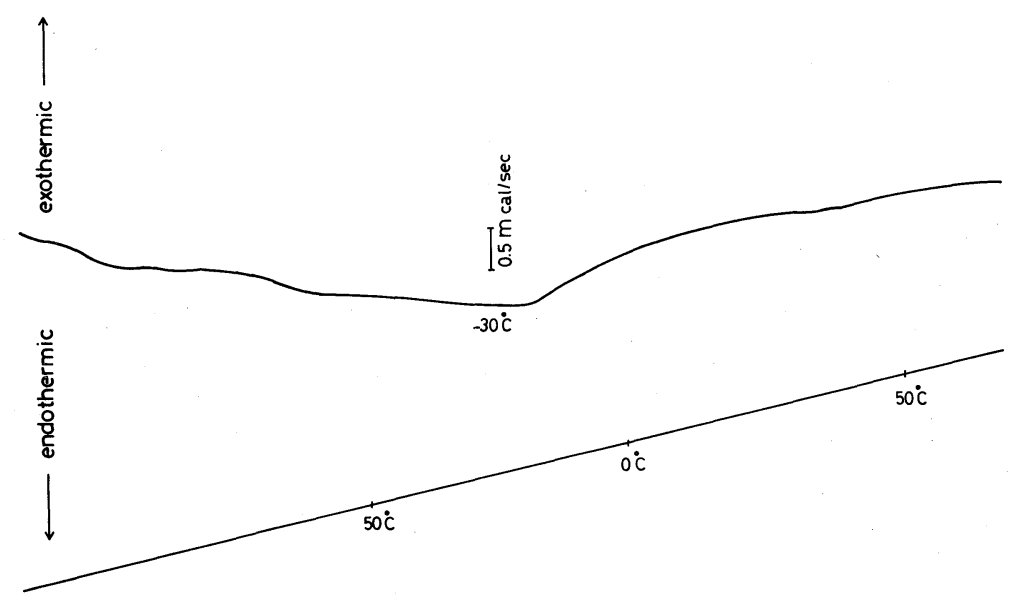

FIG. 2. Thermogram of Differential Scanning Calorimetry in Chloroform Fraction of Lipids of Ralls Janet Apples after Eleven Months of Storage at $0^{\circ} \mathrm{C}$.

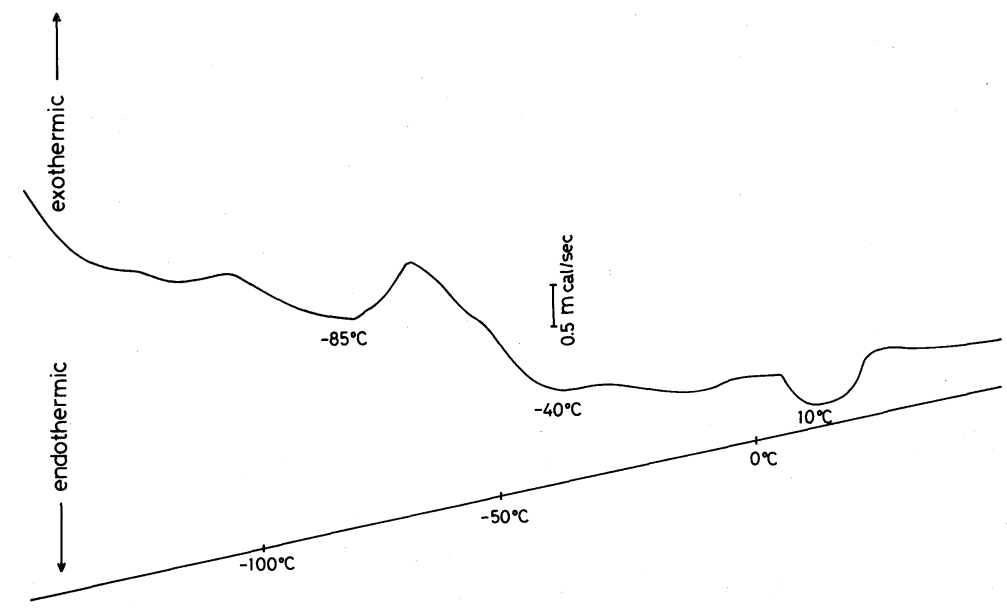

FIG. 3. Thermogram of Differential Scanning Calorimetry in Acetone Fraction of Lipids of Ralls Janet Apples after Eleven Months of Storage at $0^{\circ} \mathrm{C}$.

Janet were scrutinized. The total lipids were fractionated into phospholipid and glycolipid fractions, and examined by differential scanning calorimetry.

A broad endothermic peak was observed, having a maximum endothermic temperature at $-30^{\circ} \mathrm{C}$ in the chloroform fraction (Fig. 2). In the acetone-chloroform fraction, no peak was observed.

A broad endothermic peak was observed, having a maximum at $-85^{\circ} \mathrm{C}$, another broad endothermic peak was observed, having a maximum at $-40^{\circ} \mathrm{C}$, and then a broad endothermic peak was observed at $10^{\circ} \mathrm{C}$ in the acetone fraction (glycolipids fraction) (Fig. 3). In this fraction, the endothermic peak at $-85^{\circ} \mathrm{C}$ corresponded to the phase change temperature at $-85^{\circ} \mathrm{C}$ in the mitochondria of Ralls Janet after six months of storage at $0^{\circ} \mathrm{C}$.

In acetone-methanol $(98: 2)$ and chloroform-methanol $(8: 2)$, no peak was observed. A broad endothermic peak was observed at $-100 \sim 40^{\circ} \mathrm{C}$, having a maximum endothermic temperature of $-20^{\circ} \mathrm{C}$ in the methanol fraction (Fig. 4).

The lipid composition of the acetone fraction was characterized by thin-layer chromatography (Fig. 5). The large spots having $R f$ 


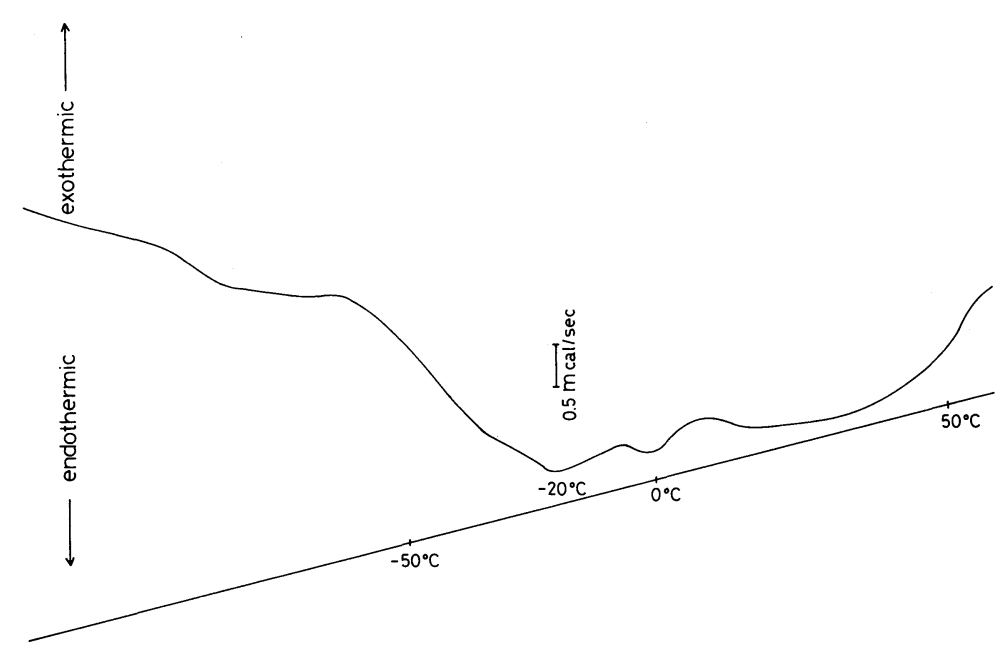

FIG. 4. Thermogram of Differential Scanning Calorimetry in Methanol Fraction of Lipids of Ralls Janet Apples after Eleven Months of Storage at $0^{\circ} \mathrm{C}$.

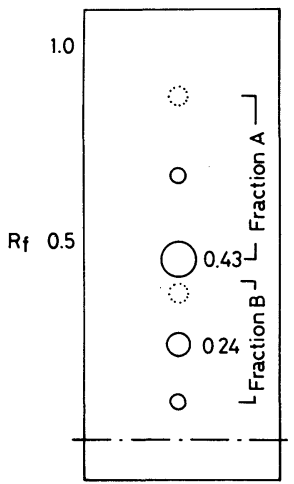

FIG. 5. Thin-layer Chromatogram of Acetone Fraction of Lipids of Ralls Janet Apples after Eleven Months of Storage at $0^{\circ} \mathrm{C}$.

Development solvent: di-iso-butylketone-acetic acidwater $(40: 20: 4, \mathrm{v} / \mathrm{v})$.

values of 0.24 and 0.43 were detected together with four other kinds of small spots. To find which spots contribute to the phase change temperature at $-85^{\circ} \mathrm{C}$, the spots were cut off of the plate and eluted with chloroformmethanol $(2: 1 \mathrm{v} / \mathrm{v})$, the A fraction with an $R f$ value of 0.43 , and the $\mathrm{B}$ fraction, with 0.43 . By differential scanning calorimetry (Fig. 6), endothermic peaks were observed at $-85^{\circ} \mathrm{C}$ and at $8^{\circ} \mathrm{C}$ in fraction $\mathrm{A}$, and endothermic peaks were observed at $-30^{\circ} \mathrm{C}$ and $47^{\circ} \mathrm{C}$ in fraction $\mathrm{B}$, so fraction A contributes to the endothermic peak at $-85^{\circ} \mathrm{C}$.
The differential scanning calorimetry of total lipids in the pulp of Ralls Janet stored at $10^{\circ} \mathrm{C}$ for one month after cold storage

The glycolipid fraction causing the endothermic peak at $-85^{\circ} \mathrm{C}$ was thought to be temperature dependent. The Ralls Janet apples after eleven months of storage at $0^{\circ} \mathrm{C}$ were transferred to $10^{\circ} \mathrm{C}$ and stored for one month. A broad endothermic peak was observed in these apples at $-20 \sim 30^{\circ} \mathrm{C}$, having a maximum endothermic peak at $2^{\circ} \mathrm{C}$, and this means that the endothermic peak shifted to a higher temperature (Fig. 7). The lipid compositions of total lipids of Ralls Janet were characterized by thin-layer chromatography (Fig. 8). The spot having $R f$ value 0.43 was not detected, and the spots in fraction $\mathrm{B}$, not contributing to a endothermic peak at $-85^{\circ} \mathrm{C}$, were detected.

This very substance, detected at $-85^{\circ} \mathrm{C}$ by DSC, found in the acetone fraction by columnchromatography, with an $R f$ value 0.43 on TLC, positive with anthrone reagent, and which disappeared in the Ralls Janet apples stored at $10^{\circ} \mathrm{C}$ for one month after cold storage, may be the cold tolerance substance. It is very interesting what kinds of fluctuation in biochemical pathways may occur during cold storage and storage at $10^{\circ} \mathrm{C}$. 


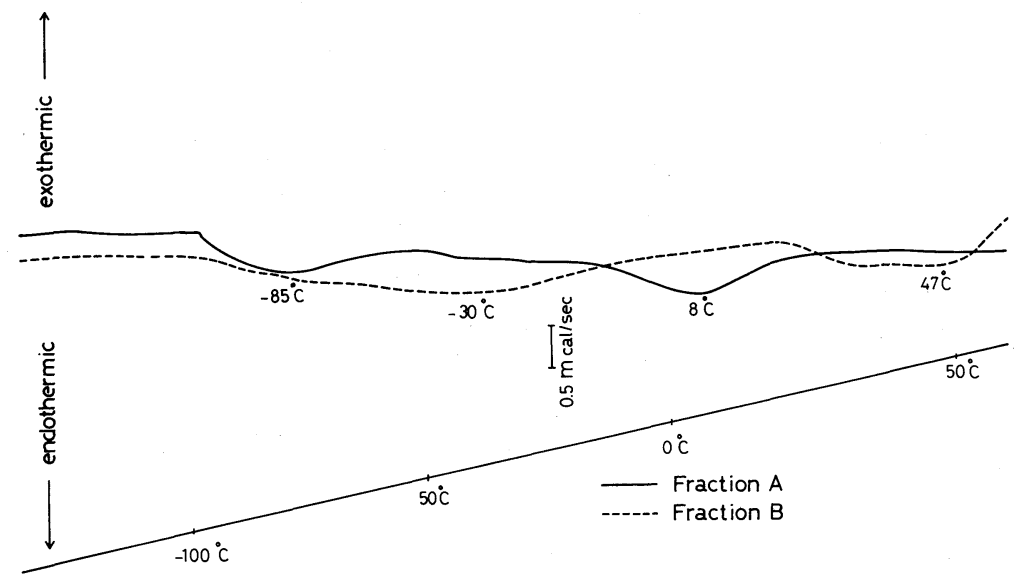

FIG. 6. Thermogram of Differential Scanning Calorimetry of Fraction A and Fraction B in Acetone Fraction of Lipids of Ralls Janet Apples after Eleven Months of Storage at $0^{\circ} \mathrm{C}$.

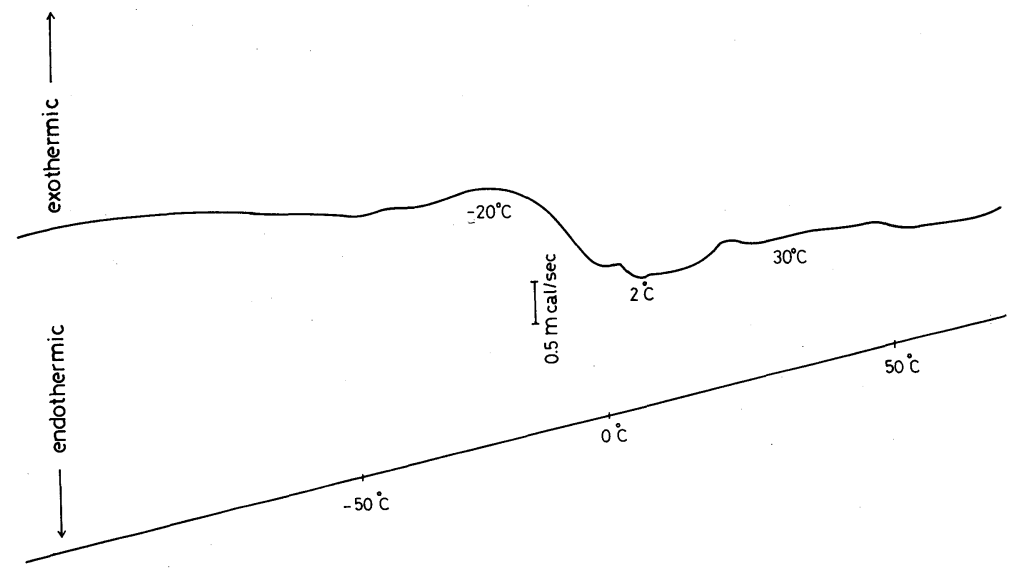

FIG. 7. Thermogram of Differential Scanning Calorimetry in Ralls Janet Apples' Total Lipids Standing at $10^{\circ} \mathrm{C}$ for One Month after Cold Storage.

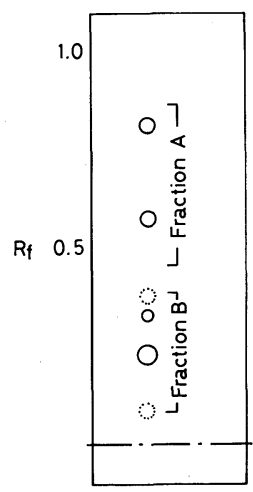

FIG. 8. Thin-layer Chromatogram of Total Lipids of Ralls Janet Apples Standing at $10^{\circ} \mathrm{C}$ for One Month after Cold Storage.

Development solvent: di-iso-butylketone-acetic acidwater $(40: 20: 4, \mathrm{v} / \mathrm{v})$.

\section{REFERENCES}

1) J. M. Lyons, T. A. Wheaton and H. K. Pratt, Plant Physiol., 39, 262 (1964).

2) N. Murata, Plant \& Cell Physiol., 24, 81 (1983).

3) J. K. Raison, J. M. Lyons, R. J. Mehlhorm and A. D. Keith, J. Biol. Chem., 246, 4036 (1971).

4) S. Kimura, M. Kanno, Y. Yamada, K. Takahashi, H. Murashige and T. Okamoto, Agric. Biol. Chem., 46, 2895 (1982).

5) S. Kimura, H. Saito and T. Okamoto, Agric. Biol. Chem., 48, 955 (1984).

6) M. L. Vorbeck and G. V. Marinetti, J. Lipid Res., 6, 3 (1965).

7) M. Noda, I. Katsura and K. Tanaka, Agric. Biol. Chem., 29, 70 (1965). 